\title{
The efficacy and safety of induction chemotherapy with taxane-based regimen in patients with locally advanced squamous cell carcinoma of the oral cavity
}

\author{
Hao-Wei Lu ${ }^{1}$, He-Yuan Hsieh ${ }^{1}$, Yi-Chun Liu ${ }^{1}$, Po-Ju Lin ${ }^{1,2}$, Weir-Chiang You ${ }^{1}$, Jin-Ching Lin ${ }^{1,2}$ \\ ${ }^{1}$ Department of Radiation Oncology, Taichung Veterans General Hospital, Taichung, Taiwan; ${ }^{2}$ Department of Radiation Oncology, Changhua \\ Christian Hospital, Changhua, Taiwan \\ Contributions: (I) Conception and design: HY Hsieh, HW Lu, JC Lin; (II) Administrative support: JC Lin, WC You; (III) Provision of study material \\ or patients: YC Liu, PJ Lin, JC Lin; (IV) Collection and assembly of data: HY Hsieh, HW Lu; (V) Data analysis and interpretation: HY Hsieh, HW \\ Lu, JC Lin; (VI) Manuscript writing: All authors; (VII) Final approval of manuscript: All authors. \\ Correspondence to: Jin-Ching Lin, MD, PhD. Department of Radiation Oncology, Changhua Christian Hospital, No 135, Nanxiao St., Changhua, \\ 500, Taiwan. Email: jinchinglin@gmail.com.
}

Background: To investigate the efficacy and safety of induction chemotherapy with a taxane-based regimen followed by local treatment in squamous cell carcinoma of the oral cavity.

Methods: From 2010 to 2017, 39 patients with previously untreated, clinical T2-4bN0-3M0, and biopsyproven squamous cell carcinoma of the oral cavity were enrolled. They received taxane-based induction chemotherapy followed by local definitive therapies [surgery, radiotherapy (RT) or chemoradiotherapy]. The majority of patients $(84.6 \%)$ underwent induction chemotherapy with CDFLEM regimen (cisplatin, day 1; docetaxel, day 8; 5-fluorouracil, day 15; epirubicin and methotrexate, day 22) every 4 weeks. The primary endpoints of this study were tumor response and toxicity of induction chemotherapy. The secondary endpoints were the impacts of local therapies (surgery or non-surgery) on overall survival (OS), locoregional recurrence-free survival (LRRFS) and distant metastasis-free survival (DMFS).

Results: Most of patients (94.9\%) belonged to stage IV disease. The primary tumor sites were buccal mucosa predominantly $(n=19)$, followed by tongue $(n=14)$. Thirty-four patients $(87.2 \%)$ could receive induction chemotherapy at least 12 weeks. Tumor response evaluated after induction chemotherapy revealed 13 patients $(33.3 \%)$ complete response (CR), 22 (56.4\%) partial response (PR), and $4(10.3 \%)$ stable disease (SD). The most common grade $3 / 4$ acute toxicities were neutropenia (66.7\%), leucopenia (56.4\%), and anemia (25.6\%). No grade 5 toxicities were found. After a median follow-up of 55 months, the 5 -year rates of OS, LRRFS and DMFS were 47.8\%, 50.8\%, and 84.8\%, respectively. The Kaplan-Meier survival analysis showed no statistically significant differences between the patients receiving surgical or non-surgical treatment (RT or chemoradiotherapy) after induction chemotherapy in terms of OS ( $\mathrm{P}=0.6237)$, LRRFS $(\mathrm{P}=0.5486)$ and DMFS $(\mathrm{P}=0.4456)$. Univariate Cox analysis also confirmed the same results.

Conclusions: Our taxane-based induction chemotherapy regimen is effective and safe for patients with oral cavity squamous cell carcinoma. Besides, either surgery or RT/chemoradiotherapy following induction chemotherapy showed similar survival outcomes.

Keywords: Induction chemotherapy; taxane; squamous cell carcinoma; oral cavity

Received: 02 April 2020; Accepted: 20 July 2020; Published: 30 September 2020.

doi: $10.21037 /$ tro-20-36

View this article at: http://dx.doi.org/10.21037/tro-20-36 


\section{Introduction}

In Taiwan, head and neck squamous cell carcinoma is the sixth most common malignancy making up more than 7,000 cases per year (1), of which the majority is the oral cavity cancer and accounts for more than 5,000 cases annually. In general, the standard treatment algorithm for locally advanced oral cavity squamous cell carcinoma is surgical resection followed by adjuvant radiotherapy (RT) or chemoradiotherapy based on postoperative pathologic high-risk features such as positive resection margins or extranodal extension (2). Attribute to the improvement of surgical technique and adjuvant treatments, the survival rate for all stages in current era is about $63-65 \%(3,4)$. In Taiwan, the 5 -year survival rates of stage I, II, III and IV oral cavity squamous cell carcinoma were $79.9 \%, 71.0 \%$, $56.5 \%$ and $35.6 \%$, respectively (1). The survival outcomes for locally advanced oral cavity squamous cell carcinoma are still unsatisfactory; therefore, multidisciplinary treatment modalities are warranted.

The role of induction chemotherapy is well established according to two landmark trials of the TAX 323 and TAX $324(5,6)$. These two studies both proved the efficacy of induction chemotherapy with docetaxel, cisplatin, and fluorouracil (TPF) regimen to unresectable head and neck cancers with overall response rate around $68 \%$. However, the oral cavity squamous cell carcinoma accounts less than $15 \%$ in both studies. It is still doubtful whether this regimen is also effective for oral cavity squamous cell carcinoma.

In our study, we try to investigate the efficacy and safety of induction chemotherapy with a taxane-based regimen followed by local treatment with surgery, RT or concurrent chemoradiotherapy (CCRT) in locally advanced oral cavity squamous cell carcinoma. Besides, survival outcomes between different local strategies (surgery versus RT/ CCRT) were also compared. We present the following article in accordance with the STROBE reporting checklist (available at http://dx.doi.org/10.21037/tro-20-36).

\section{Methods}

\section{Patients}

The eligible criteria for this retrospective study were (I) age $\geq 20$ years old, (II) biopsy-proved oral cavity squamous cell carcinoma, (III) Karnofsky performance status $\geq 70 \%$, (IV) stage III-IV but M0 based on the 7th edition American Joint Committee on Cancer TNM staging system of head and neck cancer, and (V) patients receiving taxane- based induction chemotherapy before local therapies due to unresectable tumor or refusal of surgical treatment. Exclusion criteria were (I) distant metastatic disease, (II) incomplete treatment course, and (III) synchronous double primary head and neck cancers. This retrospective study was approved by the Institutional Review Board of our hospital. From December 2010 to February 2017, 47 patients with locally advanced oral cavity cancer were retrospective reviewed. Of them, three patients refused local treatment, three had synchronous double primary head and neck cancers at initial diagnosis, and two did not complete RT after induction chemotherapy. Therefore, a total of 39 patients were eligible for analysis. All patients enrolled had complete staging workup before induction chemotherapy, which included medical history taking, physical examination, pathologic tissue proof of oral cavity tumor, baseline complete blood count and serologic biochemistry test of hepatic and renal function, chest $\mathrm{X}$-ray, abdominal ultrasonography, computed tomography (CT) scan or magnetic resonance imaging (MRI) of head and neck, and whole body bone scan. Additional positron emission tomography scan was allowed if clinical indicated. The study was conducted in accordance with the Declaration of Helsinki (as revised in 2013). The study was approved by our Institutional Review Board (IRB TCVGH No. CE17010A). Informed consent was not required for this retrospective study.

\section{Treatments}

All patients firstly received induction chemotherapy then followed by local therapies with surgery, RT or CCRT. The taxane-based induction chemotherapy regimens had been studies in our previous study (7) and modified in this study to (I) C-D-FL-EM regimen composed of cisplatin $60 \mathrm{mg} / \mathrm{m}^{2}$ on day 1 , docetaxel $50 \mathrm{mg} / \mathrm{m}^{2}$ on day 8,5 -fluorouracil $2,500 \mathrm{mg} / \mathrm{m}^{2}$ plus leucovorin $250 \mathrm{mg} / \mathrm{m}^{2}$ on day 15 , and epirubicin $30 \mathrm{mg} / \mathrm{m}^{2}$ plus methotrexate $30 \mathrm{mg} / \mathrm{m}^{2}$ on day 22 , every 4 weeks ( $n=33$ ); (II) C-D-ME regimen composed of cisplatin $60 \mathrm{mg} / \mathrm{m}^{2}$ on day 1 , docetaxel $50 \mathrm{mg} / \mathrm{m}^{2}$ on day 8 , and epirubicin $30 \mathrm{mg} / \mathrm{m}^{2}$ plus methotrexate $30 \mathrm{mg} / \mathrm{m}^{2}$ on day 15 , every 3 weeks $(\mathrm{n}=5)$; or (III) C-D-FL regimen composed of cisplatin $60 \mathrm{mg} / \mathrm{m}^{2}$ on day 1 , docetaxel $50 \mathrm{mg} / \mathrm{m}^{2}$ on day 8 , and 5 -fluorouracil $2,500 \mathrm{mg} / \mathrm{m}^{2}$ plus leucovorin $250 \mathrm{mg} / \mathrm{m}^{2}$ on day 15 , every 3 weeks $(\mathrm{n}=1)$.

After induction chemotherapy, local therapies were given with surgery, RT or CCRT. In general, surgery was the first choice, and RT (for good responders) or CCRT 
(for poor responders) could be an alternative treatment option if the patient refused surgery. The radical surgery included tumor wide excision, and/or marginal/segmental mandibulectomy, and/or functional/radical neck dissection according to preoperative clinical stage. Postoperative adjuvant RT or CCRT is indicated according to the pathologic risk features. The gross tumor volume (GTV) was contoured to post induction chemotherapy or post operative gross tumor if presented on CT-simulation. The clinical target volume (CTV) encompassed (I) the GTV, (II) initial GTV according to fusion image of CT scan or MRI before induction chemotherapy, and (III) subclinical neck lymphatic drainage area according to the primary tumor. The high-dose and low-dose planning target volume $\left(\mathrm{PTV}_{\text {high }}\right.$ and $\left.\mathrm{PTV}_{\text {low }}\right)$ were created by adding 5 mm margin to GTV or CTV, respectively. The prescribed dose was 2 Gy per fraction to the PTV $\mathrm{Phigh}_{\text {and }}$ 1.6-1.8 Gy per fraction to the $\mathrm{PTV}_{\text {low }}$ with simultaneously integrated boost. The RT was given with conventional fractionation (five days per week) with 33 (for post OP) or 35 (for no OP) fractions. The ratio of PTV receiving $100 \%$ of the prescription dose should be higher than $95 \%$ under normal organ constraints. The dose constraints for organ at risk were followed by RTOG 0522 protocol. All treatment plans were performed by $6 \mathrm{MV}$ photon with coplanar and volumetric arc therapy via RapidArc ${ }^{\circledR}$ (Palo alto, CA, USA). The concurrent chemotherapy was given with cisplatin $30 \mathrm{mg} / \mathrm{m}^{2}$ every week during RT.

\section{Study endpoints and statistical analysis}

The primary endpoints of this study were the tumor response and acute toxicities of the taxane-based induction chemotherapy. The post-chemotherapy response was classified into clinical complete response (CR), partial response (PR), stable disease (SD), or progression disease (PD) based on the Response Evaluation Criteria in Solid Tumors (RECIST version 1.1) (8). Acute toxicities of induction chemotherapy were monitor and recorded every week during treatment based on National Cancer Institute Common Terminology Criteria for Adverse Events (CTCAE) version 3.0 (9).

The secondary endpoint was the impact of local therapies (surgery or non-surgery) on overall survival (OS), locoregional recurrence-free survival (LRRFS) and distant metastasis-free survival (DMFS). The OS was calculated from the first day of induction chemotherapy to the date of death or last follow-up. The LRRFS and DMFS were calculated from the first day of induction chemotherapy to the date of locoregional recurrence and distant metastasis, respectively.

We compare the survival difference between the surgical and non-surgical treatments via Kaplan-Meier survival curve analysis and log-rank test. The univariate Cox analysis was also used to generate the hazard ratios with $95 \%$ confidence intervals between different local treatments (surgery versus RT/CCRT). All statistical analyses were calculated via SAS version 9.3, and a 2 -sided $P$ value $<0.05$ was considered statistically significant difference.

\section{Post-treatment follow-up}

Patients received post-treatment regular follow-up monthly for the first 6 months, every 3 months for following 3 years, and every 4-6 months thereafter. The head and neck CT scan was performed every 6 months for the first 2 years and annually thereafter. The $18 \mathrm{~F}$-fluorodeoxyglucose positron emission tomography scan was not a routine but was performed if clinical suspicion of recurrence.

\section{Results}

\section{Patient characteristics}

The detailed information of patients' characteristics is illustrated in Table 1. The median age was 52.2 years (range, $35.8-77.9$ years) and men were predominant $(89.7 \%)$. Most of them $(94.9 \%)$ were stage IV diseases. The main origin of the primary tumor comes from buccal mucosa (19) and tongue (14).

\section{Tumor responses after induction chemotherapy}

Thirty-four patients $(87.2 \%)$ could receive at least 12 weeks induction chemotherapy (median 12 weeks; range, 8-22 weeks); 13 patients (33.3\%) achieved clinical CR after induction chemotherapy, 22 patients $(56.4 \%)$ had PR, and four patients $(10.3 \%)$ had SD. The overall response rate was $89.7 \%$. Two of the seven patients who had initial unresectable disease (clinical T4b disease) became resectable and underwent surgery after induction chemotherapy.

\section{Toxicities of induction chemotherapy}

The toxicities during induction chemotherapy are listed in Table 2. The most common grade $3 / 4$ acute toxicity was 
Table 1 Patient characteristics between different local treatments (Surgery versus RT/CCRT) after induction chemotherapy

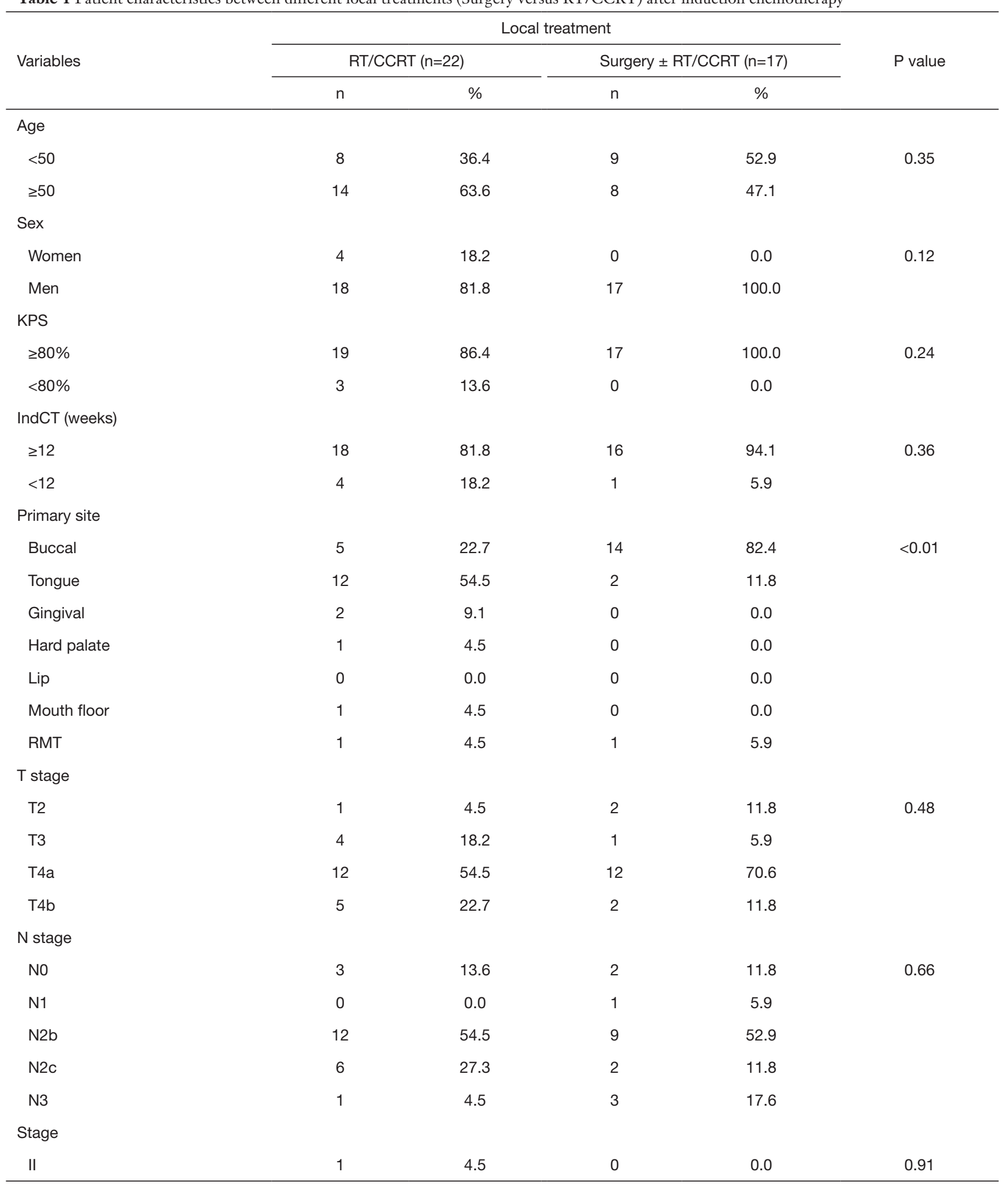

Table 1 (continued) 
Table 1 (continued)

\begin{tabular}{|c|c|c|c|c|c|}
\hline \multirow{2}{*}{ Variables } & \multicolumn{4}{|c|}{ Local treatment } & \multirow{2}{*}{$P$ value } \\
\hline & $\mathrm{n}$ & $\%$ & $\mathrm{n}$ & $\%$ & \\
\hline III & 1 & 4.5 & 0 & 0.0 & \\
\hline IVA & 14 & 63.6 & 13 & 76.5 & \\
\hline \multicolumn{6}{|l|}{ Post-IndCT response } \\
\hline Complete response & 9 & 40.9 & 4 & 23.5 & 0.36 \\
\hline Partial response & 12 & 54.5 & 10 & 58.8 & \\
\hline Stable disease & 1 & 4.5 & 3 & 17.6 & \\
\hline
\end{tabular}

IndCT, induction chemotherapy; RT, radiotherapy; CCRT, concurrent chemoradiotherapy; KPS, Karnofsky performance status; RMT, retromolar trigone.

Table 2 Acute toxicities of induction chemotherapy $(\mathrm{n}=39)$

\begin{tabular}{|c|c|c|}
\hline Toxicities & $\mathrm{n}$ & $\%$ \\
\hline \multicolumn{3}{|l|}{ Gl toxicity } \\
\hline Grade 1 & 5 & 12.8 \\
\hline Grade 2 & 17 & 43.6 \\
\hline Grade 3 & 4 & 10.3 \\
\hline \multicolumn{3}{|l|}{ Mucositis } \\
\hline Grade 1 & 5 & 12.8 \\
\hline Grade 2 & 11 & 28.2 \\
\hline \multicolumn{3}{|c|}{ Skin reaction } \\
\hline Grade 1 & 1 & 2.6 \\
\hline \multicolumn{3}{|l|}{ Hematology } \\
\hline \multicolumn{3}{|c|}{ Neutropenia } \\
\hline Grade 1 & 4 & 10.3 \\
\hline Grade 2 & 6 & 15.4 \\
\hline Grade 3 & 5 & 12.8 \\
\hline Grade 4 & 21 & 53.8 \\
\hline \multicolumn{3}{|c|}{ Leukopenia } \\
\hline Grade 1 & 8 & 20.5 \\
\hline Grade 2 & 6 & 15.4 \\
\hline Grade 3 & 20 & 51.3 \\
\hline Grade 4 & 2 & 5.1 \\
\hline
\end{tabular}

Table 2 (continued)
Table 2 (continued)

\begin{tabular}{ccc}
\hline Toxicities & $\mathrm{n}$ & $\%$ \\
\hline Anemia & 9 & 23.1 \\
Grade 1 & 18 & 46.2 \\
Grade 2 & 10 & 25.6 \\
Grade 3 & & \\
Thrombocytopenia & 9 & 23.1 \\
Grade 1 & 1 & 2.6 \\
Grade 2 & 1 & 2.6 \\
Grade 3 & & \\
Liver & 6.4 \\
Grade 1 & 6 & 15.4 \\
Grade 2 & 2 & 2.6 \\
Grade 3 & 1 & 33.3 \\
Kidney & & 7.7 \\
Grade 1 & 13 & \\
Grade 2 & 3 & \\
\hline
\end{tabular}


hematological toxicity, including neutropenia (66.7\%), leukopenia (56.4\%), anemia (25.6\%), and thrombocytopenia (2.6\%). Other grade 3/4 non-hematological toxicities were owing to gastrointestinal (10.3\%) and hepatic (2.6\%).

\section{Local treatment after induction chemotherapy}

Seventeen patients received surgery after induction chemotherapy, three patients received RT alone and 19 patients underwent CCRT. Among 17 patients who received surgery, eight patients received postoperative adjuvant RT or CCRT due to post operative pathologic risk features.

One notable thing is that 5 patients $(29.4 \%$ of 17 operated patients and $12.5 \%$ of all 39 patients) had pathologic CR after induction chemotherapy. All these 5 patients presented with clinical stage IVA diseases with primary sites of buccal mucosa $(n=4)$ and tongue $(n=1)$.

\section{Pattern of failures and survival outcomes}

After median follow-up time of 55 months (range, 7-105 months), 15 patients had locoregional recurrence alone, three patients progressed to distant metastasis alone, and two patients progressed to both locoregional recurrence and distant metastasis. At the end of analysis, 21 patients died; 10 patients were directly related to cancer progression or recurrence; 11 patients died directly due to non-cancer death (pneumonia in 6 patients; unknown in 3 patients; deep neck infection in 1 patient; massive gastrointestinal bleeding in 1 patient). None of them were classified to induction chemotherapy related death because none of them died within 3 months of induction chemotherapy. The 3-, 5-year OS rates were $59.0 \%$ and $47.8 \%$, the $3-$, 5 -year LRRFS rates were $54.5 \%$ and $50.8 \%$, and the $3-$, 5 -year DMFS rates were $89.3 \%$ and $84.8 \%$, respectively. The median time intervals from induction chemotherapy to locoregional recurrence and distant metastasis were 14 months (range, 4-52 months) and 10 months (range, $8-55$ months), respectively.

\section{Survival impacts of local therapy after induction chemotherapy}

Kaplan-Meier survival curve showed no statistically significant differences between patients receiving surgical and no surgical treatments (RT/CCRT) after induction chemotherapy in OS (5-year rates: $52.3 \%$ vs. $44.6 \%$, $\mathrm{P}=0.6237$, Figure $1 A$ ), LRRFS (5-year rates: $59.2 \%$ vs.
$43.8 \%, \mathrm{P}=0.5486$, Figure $1 B$ ) or DMFS (5-year rates: $81.3 \%$ vs. $85.7 \%, \mathrm{P}=0.4456$, Figure $1 C$ ). Univariate Cox analysis confirmed the same results. The hazards ratio $(95 \%$ confidence intervals) for death, locoregional recurrence and distant metastasis were 0.80 (0.33-1.94), 0.74 (0.27-2.01), and $1.96(0.33-11.77)$, respectively.

\section{Discussion}

Current standard treatment for locally advanced oral cavity squamous cell carcinoma comprises radical resection and postoperative RT or CCRT according to pathological high-risk features. Nevertheless, the 5 -year survival rate in modern era is still unsatisfactory $(1,10)$. In Taiwan, the survival rate for stage IV oral cavity squamous cell carcinoma is markedly poorer than stage I-III disease (5-year survival rates for stage I/II/III/IV were $79.9 \%$, $71.0 \%, 56.5 \%$ and $35.6 \%$, respectively) (1). Therefore, multidisciplinary treatment modalities with increased therapeutic strength are warranted.

Induction chemotherapy before definitive treatment, such as surgery, RT or CCRT, is a charming therapeutic strategy and option. The theoretical benefits of induction chemotherapy included (I) downstage of the tumor burden, (II) eradication of micro-metastasis, (III) increasing the possibility of radical surgery for initial unresectable disease, and (IV) enhancing the safety resection margins. The first randomized trial by Licitra et al. investigated the role of induction chemotherapy in resectable oral cavity cancers (11). In this trial, 195 patients were randomly allocated to radical surgery with or without preoperative induction chemotherapy of cisplatin plus fluorouracil, which revealed no statistically difference in OS, local disease control and distant metastasis $(11,12)$. Nevertheless, the major criticism to this study was that only patients with more than one pathologic high-risk features (positive surgical margins, invasion of soft tissues of the face, more than three nodes metastases, or extracapsular tumor spreading) underwent postoperative RT, which might be insufficient strength in current postoperative adjuvant setting.

The addition of docetaxel to cisplatin and fluorouracil as the induction chemotherapy before RT or CCRT in locally advanced head and neck squamous cell carcinoma had demonstrated improving survivals by TAX 323 and TAX 324 trials $(5,6)$. However, oral cavity squamous cell carcinoma accounts for less than $15 \%$ in these two studies. It was still controversial whether addition of taxane-based 

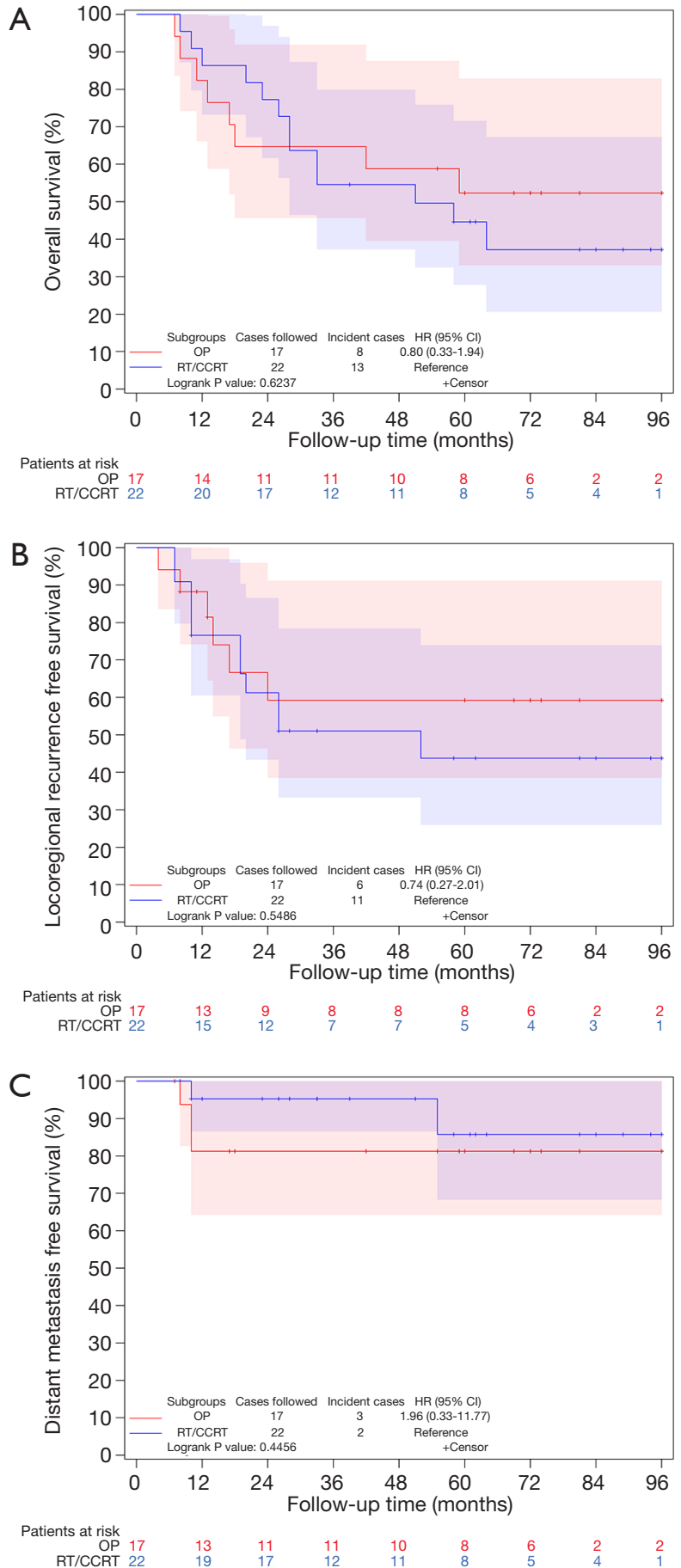

Figure 1 Kaplan-Meier survival analysis according to different local treatment (surgery versus radiotherapy/chemoradiotherapy) after induction chemotherapy: (A) overall survival, (B) locoregional recurrence-free survival, and $(\mathrm{C})$ distant metastasis-free survival. chemotherapy to induction setting could be also effective in oral cavity squamous cell carcinoma. Zhong et al. enrolled 256 patients with oral cavity squamous cell carcinoma and randomly allocated to either induction chemotherapy with TPF followed by surgery or radical surgery alone (13). This study failed to demonstrate any survival benefit by adding induction chemotherapy with TPF regimen. This study was criticized that only two cycles of induction chemotherapy was given, and patients with high-risk post operative pathologic features didn't receive postoperative CCRT routinely. Subgroup analysis showed that patients with pathologic response after induction chemotherapy had better overall outcomes compared to those with less pathologic responses or those with surgery alone (14).

The 5-year OS in our study was $47.8 \%$, which was poorer than two published randomized trials mentioned above $(12,14)$. As compared with the eligible patient composition, our study has a higher proportion of stage IV disease (95\%) compared to $27.6 \%$ of Licitra's study and $34.4 \%$ of Zhong's study, respectively. Two retrospective studies reported that taxane-based induction chemotherapy could achieve resectability in about $20 \%$ of patients with $\mathrm{T} 4 \mathrm{~b}$ or technically unresectable $\mathrm{T} 4 \mathrm{a}$ squamous cell carcinoma of the oral cavity $(15,16)$. Compared to our study, 7 patients $(17.9 \%)$ were initial unresectable diseases (clinical T4b). Two of them (28\%) became resectable diseases after induction chemotherapy and underwent radical surgical resection smoothly.

The most common grade $3 / 4$ acute adverse effect in TAX 323 and TAX 324 studies was neutropenia with the reported rates of $76.9 \%$ and $83 \%$, respectively $(5,6)$. Compared with these 2 studies, our current weekly taxanebased induction chemotherapy regimen displayed a lower incidence of grade $3 / 4$ neutropenia $(66.7 \%)$. Therefore, our taxane-based induction chemotherapy regimen is effective and safe with acceptable toxicities in locally advanced oral cavity squamous cell carcinoma.

Although our taxane-based induction chemotherapy had a higher response rate and lower toxicities than the standard TPF, an overall 5 -year locoregional recurrence rate of $51.2 \%$ after local therapy is still disappointing. It implied that more aggressive treatment strategies are warranted. Recently, cetuximab (an inhibitor of the epidermal growth factor receptor) has showed survival benefits when concurrent with radiation as a definitive 
treatment setting $(17,18)$ and combination with platinumbased chemotherapy in recurrent and metastatic head and neck squamous cell carcinoma (19). Afatinib (a potent epidermal growth factor receptor inhibitor) has revealed better progression-free survival as the second line treatment for recurrent and metastatic head and neck squamous cell carcinoma (20,21). Bevacizumab (an inhibitor of vascular endothelial growth factor) combined with chemotherapy had also shown significant better progression-free survival as the first line treatment for recurrent and metastatic head and neck squamous cell carcinoma (22). Besides, immune checkpoint inhibitors (pembrolizumab and nivolumab) have also demonstrated survival benefits as the second line treatment for recurrent and metastatic head and neck squamous cell carcinoma $(23,24)$. Therefore, combination of these newly developed drugs, such as targeted therapy agents or immune checkpoint inhibitors in either induction treatment or definitive local treatment deserves to be verified in future trials.

Although the radical surgery is the most important component of multimodality treatment strategies for locally advanced oral cavity squamous cell carcinoma, our study shows no significant survival difference between surgical and non-surgical treatment (RT or chemoradiotherapy) after taxane-based induction chemotherapy. However, this finding should be interpreted by caution due to small sample sizes and retrospective nature. A prospective randomized controlled trial should be performed to confirm our findings.

In conclusion, this study showed that our taxane-based induction chemotherapy is an effective and safe regimen for patients with locally advanced oral cavity squamous cell carcinoma. Besides, either surgery or RT/CCRT following this induction chemotherapy regimen showed similar survival outcomes.

\section{Acknowledgments}

Funding: None.

\section{Footnote}

Provenance and Peer Review: This article was a standard submission to the journal. The article was sent for external peer review.

Reporting Checklist: The authors have completed the STROBE reporting checklist. Available at http://dx.doi. org/10.21037/tro-20-36

Conflicts of Interest: All authors have completed the ICMJE uniform disclosure form (available at http://dx.doi. org/10.21037/tro-20-36). JCL serves as an unpaid editorial board member of Therapeutic Radiology and Oncology from May 2020 to Apr 2022. The other authors have no conflicts of interest to declare.

Etbical Statement: The authors are accountable for all aspects of the work in ensuring that questions related to the accuracy or integrity of any part of the work are appropriately investigated and resolved. The study was conducted in accordance with the Declaration of Helsinki (as revised in 2013). The study was approved by our Institutional Review Board (IRB TCVGH No. CE17010A). Informed consent was not required for this retrospective study.

Open Access Statement: This is an Open Access article distributed in accordance with the Creative Commons Attribution-NonCommercial-NoDerivs 4.0 International License (CC BY-NC-ND 4.0), which permits the noncommercial replication and distribution of the article with the strict proviso that no changes or edits are made and the original work is properly cited (including links to both the formal publication through the relevant DOI and the license). See: https://creativecommons.org/licenses/by-nc-nd/4.0/.

\section{References}

1. Cancer Registry Annual Report, 2016, Health Promotion Administration, Ministry of Health and Welfare, Taiwan. Available online: https://www.hpa.gov.tw/Pages/ashx/File. ashx?FilePath= /File/Attach/6071/File_5983.pdf

2. National Comprehensive Cancer Network: NCCN Clinical Practice Guidelines in Oncology: Head and Neck Cancers, Version 1; 2020. Available online: https://www.nccn.org/ professionals/physician_gls/pdf/head-and-neck.pdf

3. Siegel RL, Miller KD, Jemal A. Cancer statistics, 2020. CA Cancer J Clin 2020;70:7-30.

4. Chi AC, Day TA, Neville BW. Oral cavity and oropharyngeal squamous cell carcinoma--an update. CA Cancer J Clin 2015;65:401-21.

5. Vermorken JB, Remenar E, van Herpen C, et al. Cisplatin, fluorouracil, and docetaxel in unresectable head and neck cancer. N Engl J Med 2007;357:1695-704.

6. Posner MR, Hershock DM, Blajman CR, et al. Cisplatin 
and fluorouracil alone or with docetaxel in head and neck cancer. N Engl J Med 2007;357:1705-15.

7. Hsieh HY, Liu YC, Lin JW, et al. Prognostic effects of the metabolic tumor volume and total lesion glycolysis in patients with advanced squamous cell carcinoma of head and neck. Ther Radiol Oncol 2018;2:5.

8. Eisenhauer EA, Therasse P, Bogaerts J, et al. New response evaluation criteria in solid tumours: revised RECIST guideline (version 1.1). Eur J Cancer 2009;45:228-47.

9. Common Terminology Criteria for Adverse Events v3.0 (CTCAE) Publish Date: August 9, 2006. Available online: https://ctep.cancer.gov/protocolDevelopment/electronic_ applications/docs/ctcaev3.pdf

10. Hanna GJ, Haddad RI, Lorch JH. Induction chemotherapy for locoregionally advanced head and neck cancer: past, present, future? Oncologist 2013;18:288-93.

11. Licitra L, Grandi C, Guzzo M, et al. Primary chemotherapy in resectable oral cavity squamous cell cancer: a randomized controlled trial. J Clin Oncol 2003;21:327-33.

12. Bossi P, Lo Vullo S, Guzzo M, et al. Preoperative chemotherapy in advanced resectable OCSCC: longterm results of a randomized phase III trial. Ann Oncol 2014;25:462-6.

13. Zhong LP, Zhang CP, Ren GX, et al. Randomized phase III trial of induction chemotherapy with docetaxel, cisplatin, and fluorouracil followed by surgery versus upfront surgery in locally advanced resectable oral squamous cell carcinoma. J Clin Oncol 2013;31:744-51.

14. Zhong LP, Zhang CP, Ren GX, et al. Long-term results of a randomized phase III trial of TPF induction chemotherapy followed by surgery and radiation in locally advanced oral squamous cell carcinoma. Oncotarget 2015;6:18707-14.

15. Rudresha AH, Chaudhuri T, Lakshmaiah KC, et al. Induction Chemotherapy in Technically Unresectable Locally Advanced T4a Oral Cavity Squamous Cell Cancers: Experience from a Regional Cancer Center of South India. Indian J Med Paediatr Oncol 2017;38:490-4.

doi: $10.21037 /$ tro-20-36

Cite this article as: Lu HW, Hsieh HY, Liu YC, Lin PJ, You WC, Lin JC. The efficacy and safety of induction chemotherapy with taxane-based regimen in patients with locally advanced squamous cell carcinoma of the oral cavity. Ther Radiol Oncol 2020;4:16.
16. Rudresha AH, Chaudhuri T, Lakshmaiah KC, et al. Induction chemotherapy in locally advanced $\mathrm{T} 4 \mathrm{~b}$ oral cavity squamous cell cancers: A regional cancer center experience. Indian J Cancer 2017;54:35-8.

17. Bonner JA, Harari PM, Giralt J, et al. Radiotherapy plus cetuximab for squamous-cell carcinoma of the head and neck. N Engl J Med 2006;354:567-78.

18. Bonner JA, Harari PM, Giralt J, et al. Radiotherapy plus cetuximab for locoregionally advanced head and neck cancer: 5-year survival data from a phase 3 randomised trial, and relation between cetuximab-induced rash and survival. Lancet Oncol 2010;11:21-8.

19. Vermorken JB, Mesia R, Rivera F, et al. Platinum-based chemotherapy plus cetuximab in head and neck cancer. $\mathrm{N}$ Engl J Med 2008;359:1116-27.

20. Machiels JP, Haddad RI, Fayette J, et al. Afatinib versus methotrexate as second-line treatment in patients with recurrent or metastatic squamous-cell carcinoma of the head and neck progressing on or after platinumbased therapy (LUX-Head \& Neck 1): an open-label, randomised phase 3 trial. Lancet Oncol 2015;16:583-94.

21. Guo Y, Ahn MJ, Chan A, et al. Afatinib versus methotrexate as second-line treatment in Asian patients with recurrent or metastatic squamous cell carcinoma of the head and neck progressing on or after platinumbased therapy (LUX-Head \& Neck 3): an open-label, randomised phase III trial. Ann Oncol 2019;30:1831-9.

22. Argiris A, Li S, Savvides P, et al. Phase III Randomized Trial of Chemotherapy With or Without Bevacizumab in Patients With Recurrent or Metastatic Head and Neck Cancer. J Clin Oncol 2019;37:3266-74.

23. Cohen EEW, Soulieres D, Le Tourneau C, et al. Pembrolizumab versus methotrexate, docetaxel, or cetuximab for recurrent or metastatic head-and-neck squamous cell carcinoma (KEYNOTE-040): a randomised, open-label, phase 3 study. Lancet 2019;393:156-67.

24. Ferris RL, Blumenschein G Jr, Fayette J, et al. Nivolumab for Recurrent Squamous-Cell Carcinoma of the Head and Neck. N Engl J Med 2016;375:1856-67. 